\title{
The Potential of using Power-to-Liquid Plants for Power Storage Purposes
}

\author{
Friedemann G. Albrecht \\ Daniel H. König \\ Ralph-Uwe Dietrich \\ Institute of Engineering Thermodynamics \\ German Aerospace Center (DLR) \\ Stuttgart, Germany \\ Friedemann.albrecht@dlr.de
}

\begin{abstract}
The Power-to-Liquid (PtL) concept offers the potential to interlink the power and fuel market by producing high quality fuels from electricity and $\mathrm{CO}_{2}$. In addition, gaseous by-products from fuel synthesis can be used to generate electricity in peak load hours. In this work, a PtL concept comprising of a reversible solid oxide cell (SOC) is presented and evaluated in terms of 2014 fuel net production costs (NPC) and power storage potential. Results were compared with a reference system operating steady-state in electrolysis mode. A $100 \%$ SOC run factor was realized, whereby the SOC unit runs primarily in co-electrolysis mode. Fuel net production costs (NPC) were slightly higher for the reversible SOC system, since increased capital costs exceed the revenue from lower average electricity costs. Though, fuel costs below $1 € / \mathrm{l}$ are possible if every $\mathrm{kWh}$ of effectively stored electricity is credited with 3-9 $€ c t / k W h$, which is the typical storage costs of state-of-the-art pump storage plants.
\end{abstract}

Index Terms - Alternative fuels, energy storage, Power-toLiquid, power supply management, techno-economic analysis

\section{INTRODUCTION}

Greenhouse gas (GHG) emissions reduction in the transportation sector is a major issue of the European agenda [1]. While electric driving may be an attractive option to decrease GHG emissions in light passenger transport, at least aviation and heavy load road transportation will continue to rely on liquid fuels with high gravimetric and volumetric energy density. The production of alternative fuels from power and $\mathrm{CO}_{2}$ in the so-called Power-to-Liquid (PtL) concept can integrate the electricity and the fuel market. Thus, the large technical potential of renewable power in Europe can be utilized to reduce GHG emissions in the transport sector significantly. Additionally, future PtL plants might also be used for balancing highly fluctuating electricity generation of renewable power sources such like wind and solar power. Hydrogen can be produced in times of low electricity prices and be stored along with tail gas from Fischer-Tropsch (FT) synthesis. Stored gas can be reconverted to electricity in peak load hours. That concept requires a reversible electrolysis, notably a reversible solid oxide cell (SOC). Advantages and drawbacks of this concept shall be compared with the standard PtL concept. The technical and economic performance of PtL concepts has already been investigated in several technoeconomic studies [2-5]. König et al. [6] reported that net production costs of PtL fuel highly depend on the electricity price. Though, a constant electricity price was used for the economic evaluation neglecting the additional potential of utilizing price fluctuations on the power market.

A process model with a nominal electrolysis capacity of $100 \mathrm{MW}$, corresponding to $18.05 \mathrm{kt} / \mathrm{a}$ FT product, together with appropriate gas storage equipment was developed and implemented in flow-sheeting software.

\section{SYSTEM DESCRIPTION}

\section{A. Flexible SOC-PtL system}

Fig. 1 shows the simplified process scheme of the reversible SOC-PtL system based on a SOC. It shall be noted that commercial SOCs are currently only available at small capacities, extensive research is underway to understand the technology, to increase its maturity and to bring large scale units into market [7-8].

In Fig. 1, all streams in electrolysis (SOEC) and fuel cell (SOFC) mode are marked with blue and red arrows, respectively. In SOEC mode, a mixture of steam and $\mathrm{CO}_{2}$ is converted into syngas $\left(\mathrm{H}_{2}\right.$ and $\left.\mathrm{CO}\right)$. By adjusting the $\mathrm{CO}_{2}$ feed stream, a $\mathrm{H}_{2} / \mathrm{CO}$ ratio of approximately 2 at the FischerTropsch synthesis inlet can be achieved. With a SOEC conversion rate between $60-70 \%$, remaining $\mathrm{CO}_{2}$ shall be removed by a selexol ${ }^{\mathrm{TM}}$ unit and reused as feed-gas. To allow steady Fischer-Tropsch production even in times of power shortage, a defined fraction (separation factor $\gamma$ ) of the syngas is separated after $\mathrm{CO}_{2}$ removal, compressed to 80 bar and stored in a syngas salt cavern. For example, a SOEC run factor of $80 \%$ corresponds to a separation factor of $\gamma=0.2(20 \%$ of the syngas is stored in the salt cavern). Consequently, the fuel output of the system reduces by $20 \%$. The remaining syngas is converted to fuel in the Fischer-Tropsch reactor [9]. The 


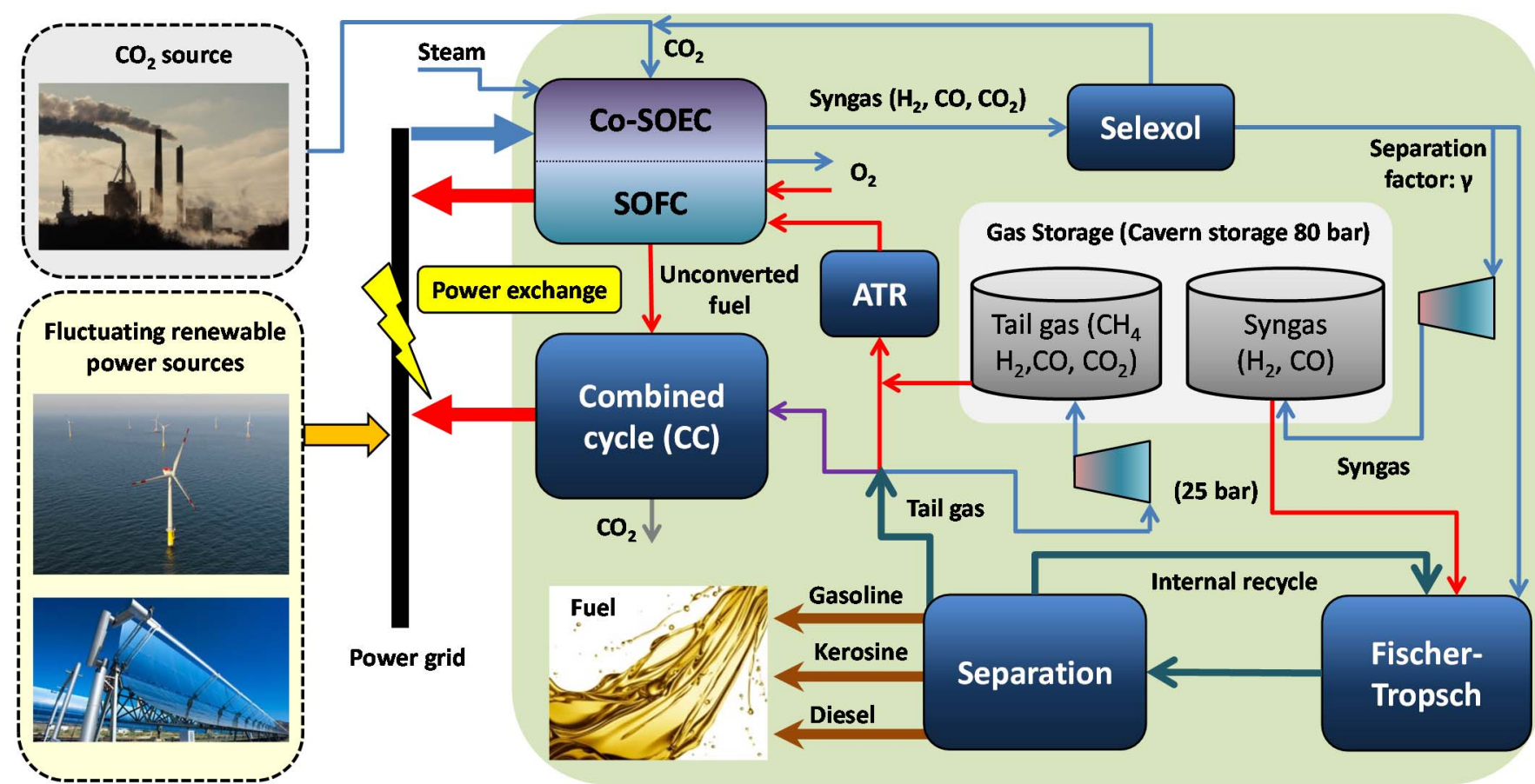

Fig. 1: Simplified process scheme of the proposed reversible SOC system

carbon number distribution of the product can be adequate described by the Anderson-Schulz-Flory (ASF) distribution as shown in equation (1).

$$
x_{n}=(1-\alpha) \cdot \alpha^{(n-1)}
$$

Alpha is an empirically determined constant describing the probability of propagation and termination of the polymerization reaction. The FT-product mixture is separated in a waxen, liquid and gaseous fraction and further refined in the separation section. Wax is processed in a hydrocracker in order to maximize the liquid fuel yield (not shown in Fig 1). Unreacted syngas is partly recycled in the FT-reactor. Methane rich tail gas from FT-synthesis is compressed to 80 bar and stored in the tail gas salt cavern.

In SOFC mode, the syngas storage is discharged to enable steady-state operation of the FT fuel synthesis plant. Tail gas both from the product separation and the second storage system is first pretreated in an autothermal reformer (ATR) before the gas stream is used in the SOC unit in order to generate electricity. The ATR unit is required to reform methane and LPG gases to avoid coking within the SOC unit. Unreacted tail gas is burned in a subsequent combined cycle to maximize electricity output.

\section{B. Reference system}

A reference system in terms of a steady state PtL system is introduced to demonstrate the advantages and drawbacks from the power flexibility of the SOC-PtL approach. The reference system deviates only slightly from the SOEC/SOFC system. By definition, the SOC unit runs in SOEC mode at all times making any storage capacity redundant. Tail gas originating from product separation is directly utilized in the combined cycle plant (illustrated with the purple arrow in Fig. 1) and power consumption from the power grid is reduced.

\section{MODELLING ASSUMPTIONS}

\section{A. Reverse SOC unit}

As no data are available on performance characteristics of large scale reverse SOC systems, typical values for small scale ( $<1$ MW installed capacity) stand-alone SOEC and SOFC were used and adopted for the required plant size [2-8,15]. The main assumptions are summarized in Table 1.

TABLE I. CHARACTERISTICS OF REVERSIBLE SOC UNIT

\begin{tabular}{lc|cc}
\hline \multicolumn{2}{c|}{ Main characteristics of SOC unit } & SOEC mode & SOFC mode \\
\hline Electrical efficiency & $(\%)$ & 0.77 & 0.70 \\
Conversion rate & $(\%)$ & 0.67 & 0.67 \\
Operating temperature & $\left({ }^{\circ} \mathrm{C}\right)$ & 800 & 800 \\
Operating pressure & $(\mathrm{bar})$ & 25 & 25 \\
Operating potential & $(\mathrm{V})$ & 1.3 & 0.70 \\
Current density & $\left(\mathrm{A} / \mathrm{cm}^{2}\right)$ & 1 & 1 \\
Total Current & $(\mathrm{MA})$ & 74.4 & 74.4 \\
\hline
\end{tabular}

The current density shall be the same in both SOC modes and the reference case. Cell degeneration due to load changes was neglected in a first attempt, but shall be investigated experimentally in detail in future products.

\section{B. Fischer-Tropsch synthesis}

As it was intended to maximize the share of the liquid product, a cobalt-catalyzed low temperature fixed bed reactor operating at $200-250{ }^{\circ} \mathrm{C}$ and 20-30 bar [9] was investigated in this work. The product distribution was described by the ASF distribution with $\alpha=0.85$. Methane yield was adjusted to $12 \%$. A conversion efficiency of $40 \%$ with regard to $\mathrm{CO}$ was assumed. An inert gas proportion of $\max 50 \%$ in the feed-gas was postulated according to [10]. This was realized by adjusting the material flow of the recycle stream.

\section{Determining the SOEC runfactor}

One mayor objective of the reversible SOC system is to enable a steady-state operation of the FT fuel synthesis plant. In SOEC mode, both gas storage systems (tail gas and syngas) 
are filled up. The storage loading rate of both systems is thereby a function of the separation factor $\gamma$. In other words, if SOEC run factor is decreased, a higher syngas portion has to be stored ( $\gamma$ is increased) to enable a steady-state FT-synthesis operation for a longer period with no syngas production. Smaller average syngas supply results in less fuel output together with less tail gas production. On the contrary, the longer the SOFC operation lasts, the more tail gas needs to be stored during SOEC mode. Fig. 2 shows, that exactly one operation point of equal tail gas production and consumption can be found. The equilibrium is indicated in Fig. 2 at an SOEC run factor of approximately $80 \%$.

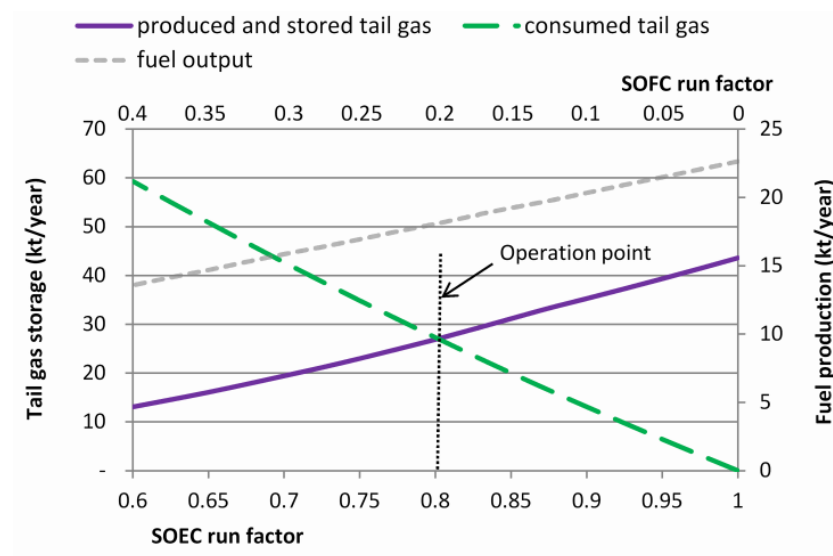

Fig. 2: Produced and consumed tail gas as a function of SOEC run factor

\section{Methodology of TECHNO-ECONOMIC ANALYSIS}

A standard approach adapted from the chemical process industry [11] was used to estimate key economic performance parameters such like capital expenditure (CAPEX), operational expenditure (OPEX) and fuel net production costs. The calculations were implemented in an in-house Tool TEPET (Techno Economic Process Evaluation Tool) to enable seamless interaction between process simulation and economic evaluation.

\section{A. CAPEX}

Equipment costs (EC) and total CAPEX were derived using the flow-sheeting simulation capacities (S) according to equation (2) and (3), respectively.

$$
\begin{gathered}
E C=E C_{\text {ref }} *\left(\frac{s}{s_{\text {ref }}}\right)^{d} * \frac{C E P C I_{2014}}{{ }^{C E P C I_{\text {ref }}}} * F_{\text {pre }} * F_{\text {mat }} \\
C A P E X=\sum\left(E C_{i} * \sum F_{j}\right)
\end{gathered}
$$

Equipment costs $\left(\mathrm{EC}_{\text {ref }}\right)$ and capacities $\left(\mathrm{S}_{\text {ref }}\right)$ of reference equipment was scaled according to the calculated capacity from the process simulation (S) using a component specific digression factor (d). The reference data of the main equipment are summarized in Table II.

TABLE II. REFERENCE EQUIPMENT COSTS

${ }^{\mathrm{a}}$ costs given in million $€(2014)$

\begin{tabular}{llcccc}
\hline \multicolumn{1}{c}{ Equipment } & $\boldsymbol{E C}_{\text {ref }}{ }^{\boldsymbol{}}$ & $\boldsymbol{S}_{\text {ref }}$ & Unit & $\boldsymbol{d}$ & $\boldsymbol{R e f}$. \\
\hline ATR & 33.2 & 400 & $\mathrm{MW}$ (thermal capacity) & 0.7 & {$[12]$} \\
FT-reactor & 17.6 & 1 & $\mathrm{~m}^{3}$ (reactor volume) & 1 & {$[13]$} \\
Gas turbine cycle & 8.47 & 25 & $\mathrm{MW}$ (power output) & 0.7 & {$[14]$} \\
Gas/liquid separator & 0.09 & 10 & m (unit length) & 0.7 & {$[11]$} \\
Hydrocracker & 7.79 & 1.13 & $\mathrm{~kg} / \mathrm{s}$ (feed mass flow) & 0.7 & {$[3]$} \\
Selexol unit & 59.5 & 9909 & $\mathrm{kmol} / \mathrm{h}$ (CO2 in feed) & 0.7 & {$[14]$} \\
SOC unit & 930 & 1 & $\mathrm{MW}$ (installed capacity) & 1 & {$[15]$} \\
Steam turbine cycle & 0.34 & 10.5 & $\mathrm{MW}$ (power output) & 0.44 & {$[13]$} \\
\hline
\end{tabular}

Data were updated with the Chemical Engineering Plant Cost Index (CEPCI), higher costs due to operation pressure and/or material requirements were considered by the multipliers $F_{\text {pre }}$ and $\mathrm{F}_{\text {mat }}$. Additional factors $\left(\mathrm{F}_{\mathrm{j}}\right)$ were multiplied with the unit equipment costs (EC) in order to account for the plant construction. The applied factors are summarized in Table III according to [11].

TABLE III. APPLIED FACTORS FOR ESTIMATING TOTAL CAPEX

\begin{tabular}{cc|cc}
\hline Factor $\boldsymbol{F}_{\boldsymbol{j}}$ & value & Factor $\boldsymbol{F}_{\boldsymbol{j}}$ & value \\
\hline Installation factor & 0.47 & Service facilities & 0.55 \\
Instrumentation and control & 0.36 & Engineering & 0.33 \\
Piping system & 0.68 & Construction expenses & 0.41 \\
Electrical systems & 0.11 & Legal expenses & 0.04 \\
Buildings & 0.18 & Contractor's fee & 0.05 \\
Yard improvements & 0.1 & Contingency & 0.1 \\
\hline
\end{tabular}

\section{B. OPEX}

Mass flows from the process simulation were multiplied with mean annual market prices (Table IV) to calculate raw material costs.

\begin{tabular}{|c|c|c|c|}
\hline Raw material / utility & \multicolumn{2}{|c|}{ Market price } & Ref. \\
\hline Clean water & 1.71 & $\left(€ / \mathrm{m}^{3}\right)$ & [16] \\
\hline $\mathrm{CO}_{2}$ & 37.75 & $(€ / t)$ & [17] \\
\hline Oxygen & 50 & $(€ / t)$ & [18] \\
\hline Power price (reference case) & 31.8 & (€/MWh) & [19] \\
\hline Selexol & 4.75 & $(€ / \mathrm{kg})$ & [20] \\
\hline Waste water & 0.56 & $(€ / \mathrm{m} 3)$ & [11] \\
\hline
\end{tabular}

TABLE IV. MARKET PRICES FOR RAW MATERIALS AND UTILITIES

Hourly market prices from the European Energy Exchange (EEX) were used in the flexible SOC model in order to exploit price fluctuations (see next subsection). Labor costs and other operational expenses for e.g. maintenance, insurances and taxes were estimated based on the methodology presented in [11]. Operational expenditures were broken down in costs for raw materials and utilities (referred to as "direct OPEX") and other operational costs (referred to as "indirect OPEX").

\section{Accounting for fluctuating power prices}

In the flexible SOC system, electricity is only consumed during SOEC mode, whereas power is exported to the power grid in SOFC mode. Expenses for power can be reduced when hydrogen is only produced in hours with low electricity prices. On the other hand, switching to SOFC mode in hours of high power costs offers the potential of maximizing revenues from power export. It was assumed that the system imports and exports electricity at the hourly market prices defined at the European Energy Exchange (EEX) in terms of the Physical Electricity Index (Phelix). Phelix can be interpreted as pure power net production costs without accounting for taxes, grid fees and levies due to the German renewable energy act (EEG). Hourly EEX market prices from 2015 [19] were rearranged in ascending order as shown in Fig. 3 (left). As a second step, average electricity purchase costs were estimated as a function of SOEC run factor assuming that electricity is only consumed in hours with low electricity costs (Fig. 3, right). Based on the supposed SOEC run factor of $80 \%$, power prices vary in the range between $-80 € / \mathrm{MWh}$ and 40 $€ / M W h$ (Fig. 3, left). At the defined operation point, annual average power prices in SOEC mode and revenue in SOFC mode of approximately $27 € / \mathrm{MWh}$ and $49 € / \mathrm{MWh}$, respectively, were identified. For the reference system with SOEC run factor of 1 , the average electricity price was $31.8 € / \mathrm{MWh}$. In order to ensure economic feasibility of the SOC-PtL concept, the profit due to utilizing the market price 

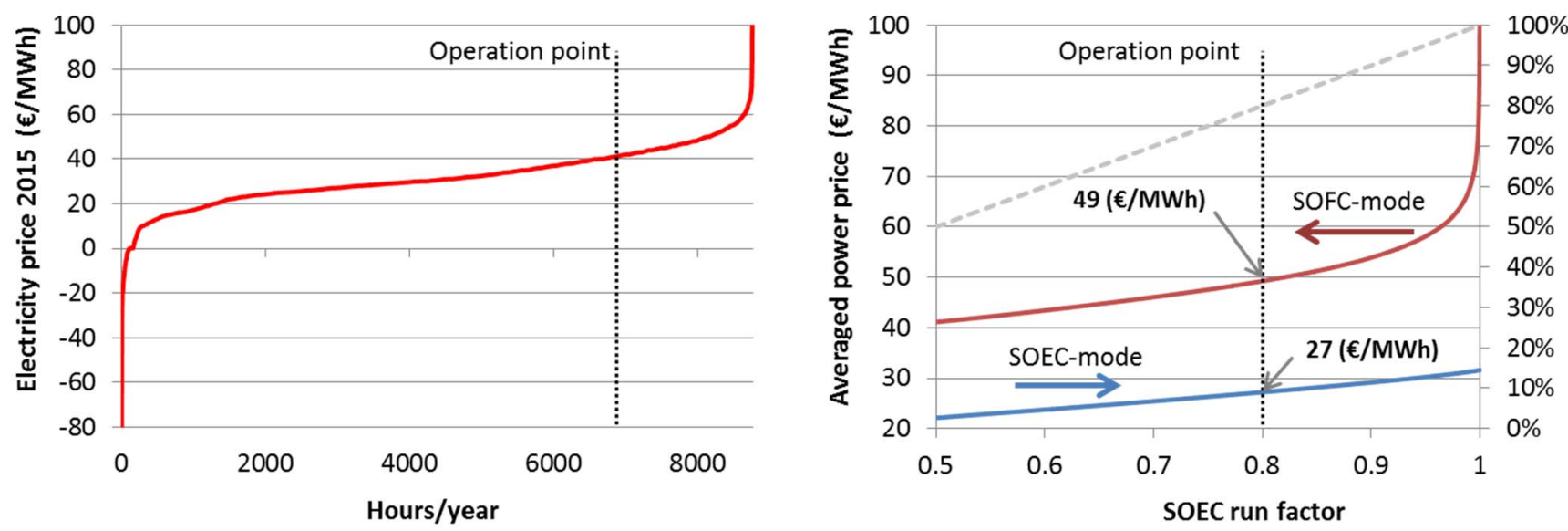

Fig.3: Listing of EEX electricity prices in ascending order according to [19] (left) and average EEX prices for importing/exporting electricity as a function of SOEC run factor (right)

difference of $22 € / \mathrm{MWh}$ has to be larger than the increased investment costs, which arises due to additional equipment in terms of the larger combined cycle plant, compressors, gas storage and ATR. Furthermore, the total yearly product output is decreased by $20 \%$ compared to the reference concept, since capacity of FT-synthesis is reduced linearly with the SOEC run factor. Hence, fuel specific investment costs (Investment costs/Product output) are even more increased.

\section{NPC}

NPC were estimated based on the total annual money flows in terms of annuity rate, OPEX and revenue from electricity export, divided by the yearly product output. An interest rate of $7 \%$ and a plant operating time of 30 years was assumed. In order to simplify calculations, a PtL plant capacity factor of $100 \%$ was assumed, corresponding to 8760 run hours per year.

\section{RESUlTS}

\section{A. Material flows and energy balance}

Table V summarizes the energy and material flows in the reference (steady-state SOEC-PtL) and power flexible SOC$\mathrm{PtL}$ system. Streams leaving the system have by convention a positive sign.

TABLE V. MATERIAL AND ENERGY FLOWS

\begin{tabular}{l|ccc}
\hline \multirow{2}{*}{ Material flows (t/h) } & \multicolumn{3}{c}{ Concept } \\
\cline { 2 - 4 } & \multirow{2}{*}{ reference } & \multicolumn{2}{c}{ reversible SOC } \\
& -25.3 & -23.6 & -13.6 \\
clean water & -8.1 & -17 & 41.7 \\
$\mathrm{CO}_{2}$ & 7.8 & 19.9 & -10.1 \\
oxygen & 2.59 & 2.06 & 2.06 \\
liquid fuel & 0 & 2.44 & -9.7 \\
syngas to cavern & 0 & 3.9 & -15.6 \\
tail gas to cavern & 23 & 12.86 & 5.04 \\
waste water & \multicolumn{3}{|c}{} \\
\hline Energy balance (MW) & -78.1 & -100.2 \\
\hline power & 0 & 18.1 & -72.4 \\
to syngas cavern (LHV) & 0 & 34.72 & -138.9 \\
to tail gas cavern (LHV) & 29.1 & 23.19 & 23.19 \\
liquid fuel (LHV) & 49 & 24.19 & 50.6 \\
losses & \multicolumn{2}{l}{} \\
\hline
\end{tabular}

The reference system is characterized by a constant electricity demand of $78.1 \mathrm{MW}$ and a fuel output of approximately 29.1 MW resulting in a power-to-fuel efficiency of $37 \%$. In the reversible SOC case, power consumption in SOEC mode is higher $(100.2 \mathrm{MW} \hat{=}+33)$. During SOFC mode, around 137.5 MW is exported to the power grid. Hence, a load change of $237 \mathrm{MW}$ is realized indicating a large potential for balancing fluctuating power sources. However, the authors are aware of power grid stability issues arising by a sudden load change of that magnitude. Though, part load operation modes are possible allowing a smooth load change. Fuel output is reduced by $20 \%$ in the reversible SOC plant due to the smaller FTsynthesis section. A considerable high Power-to-fuel efficiency of $44 \%$ was estimated for the reversible SOC system according to equation (4) based on a SOEC run factor of $80 \%$.

$$
\eta_{\text {power-to-fuel }}=\frac{23.19 \mathrm{MW}}{0.8 * 100.2 \mathrm{MW}-0.2 * 137.5 \mathrm{MW}} \approx 44 \%
$$

The significant higher power-to-fuel efficiency can be explained by the better performance of the power generation system in the reversible SOC case consisting of SOFC in series with a combined cycle plant. Thus, a very high electrical efficiency was realized.

\section{B. Economic evaluation}

CAPEX, OPEX and NPC were calculated according to the methodology presented in Chapter IV. The results are summarized in Table VI.

TABLE VI. ECONOMIC RESULTS

\begin{tabular}{l|c|c}
\hline \multicolumn{1}{c|}{$\begin{array}{c}\text { Monetary flows } \\
\text { (mio.€/year) }\end{array}$} & reference & flexible SOC \\
\cline { 2 - 3 } CAPEX & 20.95 & 24.61 \\
direct OPEX & 22.15 & 6.37 \\
indirect OPEX & 25.88 & 28.59 \\
\hline \multicolumn{2}{c}{ Total annual capital requirements (TCI) } & $\mathbf{6 8 . 9 8}$ \\
\hline \multicolumn{2}{c}{ NPC } & $\mathbf{5 9 . 5 7}$ \\
\hline fuel output $\left(\mathrm{kt} /\right.$ year) $\left(\mathrm{m}_{\text {fuel }}\right)$ & 22.69 \\
NPC (€/kg) & $\mathbf{3 . 0 4}$ & 18.05 \\
NPC (€/l) & $\mathbf{2 . 1 3}$ & $\mathbf{3 . 3 0}$ \\
\hline
\end{tabular}

Additional equipment such like salt caverns and ATR, requires significant higher capital investments for the flexible SOC concept. On the contrary, direct operational expenditures are reduced by more than $70 \%$ as a result of utilizing power price fluctuations. Thus, total annual capital requirements (TCI) are reduced by approximately $10 \%$ (Table VI). However, since fuel output is $20 \%$ reduced as well, NPC is higher in the flexible SOC concept. Hence, the flexible SOC system is economic feasible only with economic incentives in 
terms of support schemes for providing power storage capacity. Equal NPC of both the reference and reversible SOC system are achieved, if the exported electricity is financially supported with $\mathrm{c}_{\text {storage }}=1.95 € \mathrm{ct} / \mathrm{kWh}$ (required TCI reduction divided by annual SOC power production, see equation (5)), which can be interpreted as the "storage cost" for electricity in the flexible SOC-PtL system.

$$
\begin{aligned}
c_{\text {storage }} & =\frac{T C I_{\text {SOC }}-N P C_{\text {ref }} * m_{\text {fuel,SOC }}}{\text { SOFC run factor } * 8760 h * P_{\text {SOFC }}}= \\
= & \frac{59.57 \text { mio. } \frac{€}{\text { year }}-3.04 \frac{€}{\mathrm{~kg}} * 18.05 \frac{\mathrm{kt}}{\text { year }}}{0.2 * 8760 \frac{\mathrm{h}}{\text { year }} * 137.5 \mathrm{MW}}=0.0195 \frac{€}{\mathrm{kWh}}
\end{aligned}
$$

That figure shall be compared to other electricity storage costs like pump storage plants, compressed air storage systems and power-to-gas, which are given in [21] in the range of 3-9 $€ c t / \mathrm{kWh}, 4-13 € \mathrm{ct} / \mathrm{kWh}$ and $15-29 € \mathrm{ct} / \mathrm{kWh}$, respectively. Fig. 5 shows the impact of storage compensation on fuel production costs (3-9€ct/kWh, see grey area in Fig. 4). When crediting power storage costs according to current storage market prices (upper range), fuel costs below $1 € / 1$ are possible for SOC plants with electrolyzer capacities larger than $150 \mathrm{MW}$.

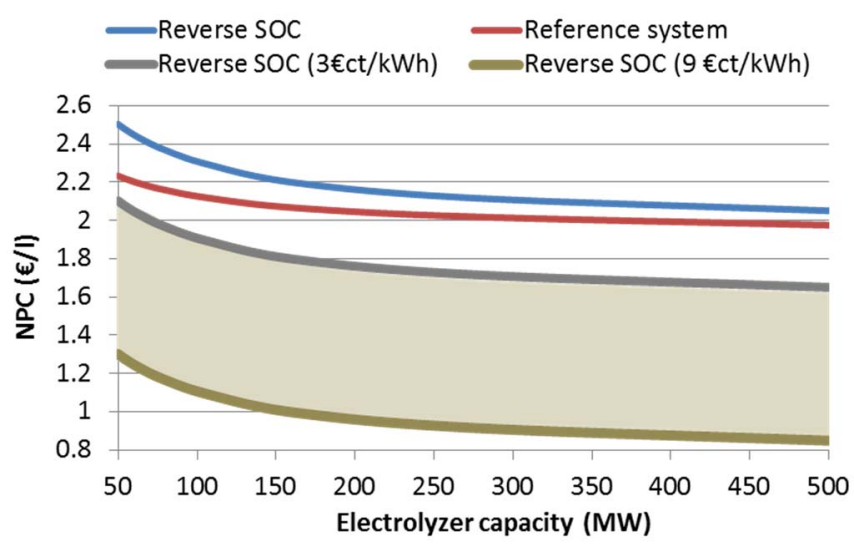

Fig. 4: NPC as a function of electrolyzer capacity and compensation for providing storage capacity

\section{CONCLUSION}

A reversible SOC PtL system was investigated and compared to a reference single SOEC system in terms of power storage potential and net fuel production costs. It was shown that reversible PtL systems can efficiently be used for power supply and demand management at low specific power storage costs when a SOC runtime close to $100 \%$ is achieved. Thereby, a load reduction of $237 \mathrm{MW}$ was realized by switching from electrolysis to fuel cell mode. Though, NPC of liquid fuel are slightly higher compared to the reference case when no compensation is paid for providing storage capacity. On the contrary, net fuel production costs below $1 € / 1$ can be achieved when a premium of 7-9 €ct/kWh is paid for stored electricity, which is in the range of specific storage costs of state-of-the-art pump storage power plants.

\section{REFERENCES}

[1] European Commission, "White paper - Roadmap to a single European Transport Area - Towards a competitive and resource efficient transport system," Brussels, Mar. 2011.

[2] G. Cinti, A. Baldinelli, A. Di Michele, U. Desideri, "Integration of Solid Oxide Electrolyzer and Fischer-Tropsch: A sustainable pathway for synthetic fuel,” Applied Energy, vol. 162, pp. 308-320, 2016.
[3] W. L. Becker, R. J. Braun, M. Penev, M. Melaina, „Production of Fischer-Tropsch liquid fuels from high temperature solid oxide coelectrolysis units," Energy, vol. 42, pp. 99-115, 2012.

[4] J. P. Stempien, M. Ni, Q. Sun, S. H. Chan, "Thermodynamic analysis of combined Solid Oxide Electrolyzer and Fischer-Tropsch processes," Energy, vol. 81, pp. 682-690, 2015.

[5] A. Tremel, P. Wasserscheid, M. Baldauf, „Techno-economic analysis for the synthesis of liquid and gaseous fuels based on hydrogen production via electrolysis, “ International Journal of Hydrogen Energy, vol. 40, pp. 11457-11464, 2015.

[6] D. H. König, M. Freiberg, R.-U. Dietrich, A. Wörner, „Techno-economic study of the storage of fluctuating renewable energy in liquid hydrocarbons, “ Fuel, vol. 159, pp. 289-297, 2015.

[7] N. Q. Minh, M. B. Mogensen, „Reversible Solide Oxide Fuel Cell Technology for Green Fuel and Power Production," The electrochemical Society Interface, vol. 22, pp. 55-62, winter 2013.

[8] J. T. S. Irvine, P. Commor, "Solide Oxide Fuels Cells: Facts and Figures," vol. I. London: Springer Verlag, 2013.

[9] A. de Klerk, "Fischer-Tropsch Refining," vol. I. Weinheim: Wiley-VCH Verlag, 2011.

[10] P. Kaiser, A. Jess, „Modeling of Multitubular Reactors for Iron- and Cobalt-Catalyzed Fischer-Tropsch Syntheses for Application in a Power-to-Liquid Process,“ Energy Technology, vol. 2, pp. 486-497, 2014.

[11] M. S. Peters, K. D. Timmerhaus, R. E. West, “ Plant Design and Economics for Chemical Engineers," vol. 5., published by Mc Graw Hill, 2004.

[12] M. J. A. Tijmensen, A. P. C. Faaij, C. N. Hamelinck, M. R. M. van Hardeveld, „Exploration of the possibilities for production of Fischer Tropsch liquids and power via biomass gasification," Biomass Bioenergy, vol. 23, pp. 99-115, 2002.

[13] P. Kerdoncuff, „Modellierung und Bewertung von Prozessketten zur Herstellung von Biokraftstoffen der zweiten Generation,“ Ph.D. dissertation, Fakultät fur Wirtschaftswissenschaften, Universität Karlsruhe, 2008.

[14] C. N. Hamelinck, „Outlook for advanced biofuels,“ Ph.D. dissertation, Faculteit Scheikunde, Utrecht University, 2004.

[15] B. V. Mathiesen, I. Ridjan, D. Connolly, M. P. Nielsen, P. V. Hendriksen, M. B. Mogensen, S. H. Jensen, S. D. Ebbesen, "Technology data for high temperature solid oxide electrolyser cells, alkali and PEM electrolysers," Department of Developming and Planning, Aalborg University, 2013.

[16] Statistisches Bundesamt, "Entgelt für Trinkwasserversorgung privater Haushalte in Deutschland 2005 und 2014," Deutsches Statistisches Bundesamt, 2014.

[17] P. Markussen, J. M. Austell, C.-W. Hustad, „A CO2-Infrastructure for EOR in the North Sea (CENS): Macroeconomic Implications for Host Countries,“ paper No. 234, Sixth International Conference on Greenhouse Gas Control Technologies., Kyoto, 2002.

[18] P. Rao, M. Muller, "Industrial Oxygen: Its Generation and Use," ACEEE Summer Study on Energy Efficiency in Industry, 2007.

[19] European Energy Exchange (EEX), "Average Electricity Price in Germany 2014 based on the Physical Electricity Index (Phelix)," Energinet.dk, udtræk af markedsdata, 2015.

[20] C. Chen, „A Tehonical and Economical Assessment of CO2 Capture Technology for IGCC Power Plants,“ Ph.D. dissertation, Carnegie Mellon University, 2005.

[21] N. Hartmann, L. Eltrop, N. Bauer, J. Salzer, S. Schwarz, M. Schmidt,"Stromspeicherpotenziale für Deutschland,“ Zentrum für Energieforschung Stuttgart (Zfes), Universität Stuttgart, Juli 2012. 